UDC $616.23 / 25-000.34+616-089.843$

Polyachenko Y. B. ${ }^{1}$, Nikonenko O. S. ${ }^{2}$, Salyutin R. V. ${ }^{1,3}$, Komarov M. P. ${ }^{3}$, Palyanitsya S. S. ${ }^{3}$, Boris R. M. ${ }^{3}$

${ }^{1}$ A. A. Shalimov National Institute of Surgery and Transplantology of NAMS of Ukraine, Kyiv, Ukraine

${ }^{2}$ Zaporizhzhya Medical Academy of Postgraduate Education of Ministry of Health of Ukraine, Zaporizhzhya, Ukraine ${ }^{3}$ Coordinating Centre of Transplantation for Organs, Tissue and Cells, Ministry of Health of Ukraine, Kyiv, Ukraine

e-mail: r.salutin@mail.ru

\title{
CELL TRANSPLANTATION: REGULATORY ASPECTS, PROSPECTS AND TRENDS IN THE CLINICAL USE
}

\section{ABSTRACT}

This is review of the current state of cell and tissue technologies in Ukraine and in other countries. The advances and problems of domestic and foreign regulatory framework of this field are discussed in a framework of the legislations governing research and clinical application of cell technologies in Ukraine.

KEYWORDS: cell and tissue transplantation, clinical trials, biotechnological product.

Over the last decade the number of allogeneic or autologous cell and tissue transplantations has increased dramatically in the world. The potential clinical use of autologous stem cells of the allogenic and xenogenic origin are of a particular interest for researchers and clinicians.

Unique and unexplored characteristics of stem cells, aura of mystery and mystification and gradual disappointment of clinicians with pharmaceutical products (lack of efficiency, their aggressiveness, rise of toxicity) determine the interest of practical medicine to stem cell research. The future of modern medicine and the trends of its development are associated with stem cell transplantation.

According to public sources, in 2002, the world had registered more than 30 biotechnology companies with a budget of over 1.5 million dollars, involved in research, production and clinical application of cell and tissue transplants, including genetically modified materials. Their number increases progressively every year. By the end of 2011, over 300 large leading biotechnology companies have been working around the world; and the number of small laboratories and research centers included tens of thousands.

Noteworthy is the fact that the number of stem cells researches, namely, scientific papers classified from «privacy» to «secret» have been rocketing. For example, in 2000 , a few of the fundamental researches on stem cell properties were published, and more than 2.5 thousand technologies and methods associated with stem cells were patented by leading biotech companies. Confidentiality of research and scientific developments is related to the financial benefits of the advanced cell technology application as well. In 2005, the world market of cell technologies was estimated at 26.6 billion dollars, and in 2010 more than 56.2 billion dollars. According to experts, by 2015 the financial component of cell technology will be assessed over 96.3 billion.
Considering the above, one can predict rapid implementation of theoretical and experimental innovation into clinical practice. Despite the comparatively short-term experience of clinical stem cell transplantation (apart from transplantation of hematopoietic stem cells from bone marrow or peripheral blood), this method joined modern approaches to the treatment of serious congenital and acquired diseases. Donor's hematopoietic stem cells include umbilical cord blood used for restoration of hematopoiesis depressed by the hematological diseases and chemo-radiotherapy.

Multipotent mesenchymal stem cells are widely used in the treatment of patients with complications of coronary artery disease - myocardial infarction, chronic heart failure. Cell transplantation improves the functioning of cardiac muscle. Due to the restoration of myocardial tissue and local microcirculation, it increases the cardiac output.

Methods of cell transplantation are being actively implemented in the treatment of hopeless patients with incurable diseases previously: severe strokes, neurodegenerative diseases, injuries of the brain and spinal cord. Cord blood stem cells have been undergoing clinical trials in patients with AIDS. Methods of cell and tissue transplantation are included into treatment of patients with disorders of bone and cartilage system, liver diseases, diabetes and defects of skin and soft tissue.

In addition, cell transplantation is an alternative to organ transplantation or preliminary stage of donor organ transplantation. Cell and tissue transplantation can solve largely the therapeutic issues caused by organ transplantation.

Biotechnology companies (e.g. Geron Corp.), using the cellular material, have been already producing cell products and biomaterials for substitution therapy in clinical practice. In the nearest future they can be used for creating of the bioengineered organs and tissues suitable for short- or long-term functioning. 
The unique characteristics of the stem cells and the horizons of cell transplantation application determine the close attention of the governments. Most of the studies and clinical trials in this field are funded by government. In some countries (e.g. China) everything related to stem cells is a priority and competence of the state.

Innovative aspect, medical, financial and social prospects of cell/ tissue transplantation and a number of features of this healthcare area (ethical aspects, commercial and state secret, information wars, etc.) determine the desire of the government to regulate clearly the cell transplantation activities and production of cell and tissue transplants in biotech laboratory.

The United States is the most active country in the creation of regulatory framework for using and study of stem cells and production of cell/tissue transplants. The U.S. currently has the most advanced regulatory framework for cells, tissues and products of human origin. Since 1997, the Food and Drug Administration (FDA) has introduced a new regulatory approach towards products based on tissues and cells of human origin. The basic rules were published. They implement appropriate regulations on registration of transplants, matching of donors and proper quality of medical practice. In addition, FDA regulates the use of xenografts and products, combining biological products and medical devices, such as xenogeneic cells, which are an integral device for extracorporeal desintoxication. To obtain a permit for registration and production of cell/tissue transplants, the company is obliged to submit to the Center for Biologics Evaluation and Research of FDA documents on production technology and safety of cell/ tissue transplants for clinical use.

Until recently the national legislation, regulating cell and tissue transplantation and producing transplants, was significantly different in countries of the European Union. In fact, only in 2007 the Regulation \# 1394/2007 of the European Parliament and of the Council on advanced therapy medicinal products was adopted. Regulation on preparations for advanced methods of therapy (preparations for gene therapy, treatment with somatic stem cells and tissue engineering products) is special in relation to the 2001/83/EC. Such medications, as noted in the decision, must comply with all the requirements that are set to biotech products and products of other types. Requirements for the quality and production process of biotechnological product and for the order of preclinical and clinical trials of safety and efficiency of cell or tissue transplant are clearly described. The statutes of the regulatory framework clearly indicate the required production of biotech products under GMP, adapted according to the technological process of manufacturing and the specific characteristics of the graft.

The Directive does not apply to cell transplants, which are not routinely prepared. They are used in the producer country exclusively under the responsibility of health care professionals, conducting a special treat of a patient using this type of cell or tissue transplant. Since the expertise of such products requires specific knowledge and demands, the European Medicines Agency is planning to create a Committee of the advanced therapy methods.

In Russian Federation the regulatory documents related to stem cell and tissue transplants are still being developed. In fact, today the federal rules of conducting clinical trials of cell and tissue transplants are absent. The Academic Councils of scientific and research institutes, organizations and directors of clinics are in charge of clinical trials entirely. Such situation leads to lack of clear requirements for trials and their objective assessment. Temporary instruction "On the research in the field of cell technology and its using in institution of health» and also Order of the Ministry of Health of Russian Federation «On the development of cell technology in the Russian Federation» do not fully satisfy the modern requirements and realities of the time.

Developed by the Ministry of Social Development of the Russian Federation the draft law «On biomedical cell technology» has been discussed by the medical community for more than two years. But, a clear understanding of the improvement of this bill is not obtained. Thus, the proposed bill is missing an urgent issue solution about the procedure of registration and patenting of cell and tissue transplants as a commercial product for clinical use. Also, there is no clear answer to the question who will be the main coordinator and evaluator of clinical trials. Moreover, analyzing the bill cursory, we may suppose this regulation is an extended version of Order of the Ministry of Health of Ukraine of October 10, 2007 \# 630 «0n approval of the procedure of clinical trials of tissue and cell transplants and expert evaluation of clinical trial materials». A significant drawback of the Law "On biomedical cell technology" is a limitation of sources of cell and tissue transplants, prohibiting actually the work with materials of embryonic and fetal origin.

In Ukraine, the use of cell and tissue transplants in clinical practice is based on the Law of Ukraine "On the transplantation of organs and other anatomical materials into a human", decrees of the Cabinet of Ministers of Ukraine and many regulatory documents issued by the Ministry of Health of Ukraine. The existing regulatory framework for cell and tissue transplants allows the clinical application of different types of anatomical material, autologous and allogeneic origin. In addition, the legislation handled actually all the requirements for carrying out activities related to cell/tissue transplantation, especially the clinical application of cell and tissue grafts. According to the requirements, the clinical use of cell and tissue transplants derived from anatomical material both, autologous and allogeneic or xenogeneic origin, is permitted only after the clinical trials. Requirements for clinical trials are clearly described in Order of the Ministry of Health of Ukraine on October 10, 2007 \# 630 «0n approval of the procedure for clinical trials of tissue and cell transplants, and expert evaluation of clinical trials materials, and amending the procedure for conducting clinical trials of medicinal products and expert evaluation of clinical trial materials approved by the Order of Ministry of Health of Ukraine on February 13, 2006 \# 66»

By the legislation of Ukraine, namely by the Law of Ukraine "On the transplantation of organs and other anatomical materials into a human" and the Decree of the Cabinet of Ministers of Ukraine on September 5, 2007 \# 1100 "On measures on organization of health care institutions and research institutions related to transplantation of organs, tissues and cells", the Coordination Centre for Transplantation of Organs, Tissues and Cells of Ministry of Health of Ukraine is charged as a basic institution that conducts and evaluates the results of clinical trials of cell and tissue grafts.

Currently, according to this order, clinical application of cell and tissue transplantation in a treatment of patients with pancreonecrosis is allowed. Stem cells from cord blood and umbilical cord tissue are used as transplants. They are produced in the biotechnology laboratory of Institute of Cell Therapy.

Also, clinical trials that study the effectiveness of cell/tissue transplants in the treatment of patients with traumatic and burn injuries, defects of the soft tissue, coronary heart disease, and chronic lower limb ischemia are been finished. In these clinical trials, conducted at the V. K. Husak State Institute of Urgent and Recovery Surgery NAMS Ukraine, the autologous bone marrow cells were used.

At the A. A. Shalimov National Institute of Surgery and Transplantology NAMS of Ukraine the clinical trials are almost completed. They concern the determination of the efficiency of cell transplants derived from fetal material and autologous adipose tissue in patients with chronic lower limb ischemia caused by non-reconstructable peripheral artery disease. The preliminary results of clinical trial testify to the absolute prospects of cell transplantation in the treatment of these patients.

Planning for a new clinical study is carried out. This study aims to determine the effectiveness of transplantation of cord blood cells and fetal material in correction of cardiomyopathy in the patients with complications of coronary heart disease.

Researchers from Odessa National Medical University in collaboration with physicians of Odessa Regional Hospital are working at the introduction into clinical practice of the method of transplantation of autologous hematopoietic stem cells isolated from peripheral blood in the patients with ischemic heart disease. 
Clinicians from the 0. P. Romodanov State Institute of Neurosurgery NAMS Ukraine started clinical trials to determine the efficiency of the use of multipotent mesenchymal stem cells derived from autologous adipose tissue in the treatment of degenerative and dystrophic processes in the intervertebral discs.

The results of using of stem cells from cord blood and fetal tissue in the treatment of patients with cerebral palsy, Duchenne muscular dystrophy, complications of brain and spinal cord trauma are positive and open up new horizons and prospects for treatment of severe neurological diseases.

A prospective source of stem cells is cord blood, used for the treatment of patients with oncohematological diseases. In 2010, the number of transplantations (in people under 18 years) of cord blood stem cells in the United States exceeded the transplantations of bone marrow cells. That primarily shows prospects, efficacy and safety of their clinical application.

According to the world trends, in Ukraine the using of cord blood preparations is rapidly developing in patients with non-oncohematological diseases, namely chronic limb ischemia, hepatitis, including viral etiology, hepatic cirrhosis, diabetes and more. A prospective is the use of cord blood transplantation in the treatment of patients with cancer pathology, such as after courses of severe chemo-radiotherapy.

Results of clinical application of stem cells testify to the absolute efficiency of cell transplantation in the treatment of severe diseases and pathological conditions. Besides the medical efficiency of application of cell transplantation, there is a significant socio-economic component: the time to hospitalization reduction, more rapid social and labor rehabilitation, reducing of the fatal cases, disabling surgery and its associated payments.

However, one of the main problems is the illegitimate and clinically inadequate using of cell transplants in clinical practice, including stem cells of autologous origin. This leads to discrediting of modern treatment methods. Considering actuality and unconditional prospects of cell transplantation, the interest of the state in the development of new medical technologies and the need to control the activities related to cells and tissues transplantation, creation of a unified governmental organization, conducting all activities related to this area of transplant aid, remains.

In addition, there is a need to create a unified registry of cell and tissue transplants designed for clinical use. This need is caused by impossibility to register in the Pharmacopoeia cell or tissue grafts composed of living cells and tissues along with medical preparations and medical products. Living cell system is not static, but dynamic and not stable. It can be hardly regulated in the functionality of one or several biochemical processes required as evidence of the effectiveness of medical product. Therefore, most experts in cell and tissue transplantation insist on creation of such list. Creating a register solves critical and controversial issues related to standardization and regulation in the creation and clinical application of autologous and allogeneic cell and tissue transplantation.

The forming of register is not possible without well-equipped qualified laboratory for quality control of cell and tissue grafts. This laboratory will minimize the risk of getting poor and dangerous transplant by a patient and will prevent a possible infection. These issues cannot be solved without a unified public service for transplantation, combining all directions of transplant aid, including transplantation of cells and tissues. Similar in this area services and agencies are quite successful in Europe and America.

The important point is to take under governmental control, through licensing, the activities of banks of human cord blood and other tissues and cells. Today these structures are not only a «storage» of address autologous cord blood, but they are also biotechnological laboratoriesproducers of cell or tissue transplants of autologous and donor origin. Therefore, taking into state control an important and significant segment of the healthcare industry, namely banks of cells, are quite predictable and necessary steps. This primarily provides a biological defense of a patient, needing cell and tissue transplantation and elevates to a higher quality the specialized medical care.

Today biotechnological treatment, based on the latest results of stem cell study, is the most promising area of healthcare. That is a kind of a technology platform for the medicine of the future. Industry of biomedicine and stem cells has a high commercial, medical and social significance. Countries, possessing such technology, have significant development prospects in the healthcare industry and a guarantee of national safety.

At present, Ukraine has stored unique achievements in the study of stem cell properties and their influence on the course of severe diseases and pathological states. However, the negative aspects of economics and funding of medical science are questioning further development of biotechnology and threaten the national safety of Ukraine. Only the combined efforts of the governmental and the private sector of the economy can save the heritage of past generations and develop the field of cell and tissue transplantation.

\section{REGULATORY FRAMEWORK OF CLINICAL USE OF CELL AND TISSUE TRANSPLANTS IN UKRAINE}

- Law of Ukraine «On the transplantation of organs and other anatomical human materials» of July 16, 1999 \# 1007-XIV (with amendments and supplements).

- Decree of the Cabinet of Ministers of Ukraine «On certain issues of the law of Ukraine. On the transplantation of organs and other anatomical human materials» of April 24, 2000 \# 695 (with amendments and supplements).

- Decree of the Cabinet of Ministers of Ukraine «On measures for the organization of health care institutions and scientific institutions related to the transplantation of organs, tissues and cells» of September 5, 2007 \# 1100.

- Decree of the Cabinet of Ministers of Ukraine «On approval of the national program «Transplantation» until 2012 » 0 0ctober 8, 2008 \#894.

- Order of the Ministry of Health of Ukraine «On the regulatory framework improvement and the adaptation of Ukraine to European standards in the field of transplantation of organs, tissues and cells» of September 28, 2006 \# 650 (with amendments and supplements).

- Order of the Ministry of Health of Ukraine and Academy of Medical Sciences of Ukraine «On approval of measures of Ministry of Health and Academy of Medical Sciences of Ukraine on the implementation of the national program «Transplantation" until 2012» of March 12, 2009 \# 155/24.

- Order of the Ministry of Health of Ukraine «On approval of the list of human tissues and cells, which are allowed in activities of banks of umbilical cord blood human tissues and cells» of April 20, 2012.

- $\quad$ Order of the Ministry of Health of Ukraine "On approval of Licensing Requirements for economic activity of banks of cord blood and other human tissues and cells» of April 10, 2012 